\title{
Obituary of Professor Mauro Francaviglia
}

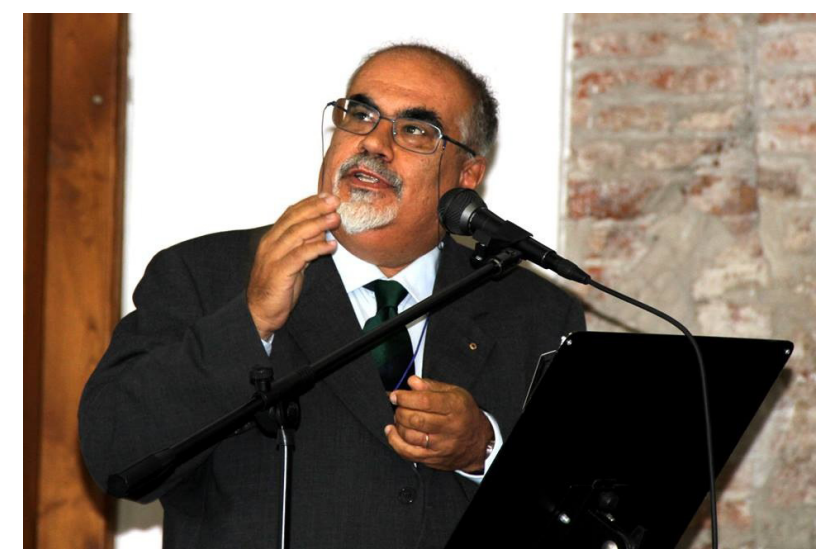

Mauro Francaviglia was born in Torino, on 22nd June 1953 and passed away in Cosenza, on 24th June 2013. He graduated, magna cum laude, in Mathematics at the University of Torino in 1975. He held the position of Full Professor of Mathematical Physics at the University of Torino since 1980, when he was 27 years old. He was considered an extremely valid researcher and he was one of the best Italian Mathematical Physicists of his generation.

Mauro started his research activity in General Relativity, as a classical relativist, and his scientific interests covered a wide range of topics, including the application of Differential Geometry in Mathematical Physics, Classical Mechanics, Field Theories, Calculus of Variations, Symmetries and Conservation Laws, Quantization, Thermodynamics and, in late years, Extended Theories of Gravitation. Author of over 250 papers, three monographs and 11 encyclopedia long entries, Editor of 19 volumes of Proceedings and Director of two CIME courses. He organized 20 national and international conferences, among which several national conferences in General Relativity and the World Conference GR14 (Florence, 1995). He has been the Director of several national and international research projects and he held over 300 invited lectures at various institutions in Italy and abroad. He supervised several successful Ph.D. students.

Mauro has been a member of the Scientific Council of GNFM-CNR (1980-1996), a co-founder (1984) and Managing Editor of "Journal of Geometry and Physics", a co-founder (1990) and President (1990-1996 and 2008-2012) of the Italian Society for General Relativity and Gravitation (SIGRAV). He was a life member of the 
International Society for General Relativity and Gravitation and he served as a member of the Board of the ISGRG for nine years (1986-1995). He was an associate editor of the Journal of General Relativity and Gravitation, since 1999, and Managing Editor of the "International Journal of Geometrical Methods in Modern Physics".

Italian relativists will definitely miss his scientific competence and enthusiasm.

Marco Ferraris, Guido Magnano, Lorenzo Fatibene, Marcella Palese, Ekkehart Winterroth, Monica Capone, Simon Garruto and Silvio Mercadante 